\title{
ENVENOMATION BY THE MALAGASY COLUBRID SNAKE
}

\section{Langaha madagascariensis}

\section{D'CRUZE NC (1)}

(1) Frontier, The Society for Environmental Exploration, London, UK.

ABSTRACT: This report documents a case of envenomation by a Malagasy opisthoglyphous snake, Langaha madagascariensis. The snake bit the finger of a healthy adult man who was attempting to record its morphological measurements as part of a biodiversity survey which was being conducted in the extreme north of Madagascar. Symptoms of this case included severe local pain accompanied by observable swelling which lasted for several days. The present observations indicate that bite by $L$. madagascariensis potentially causes notable physiological effects in humans although the snake is generally calm and reluctant to bite unless provoked.

KEY WORDS: Madagascar, colubrid, Langaha madagascariensis, envenomation, opisthoglyph, Duvernoy's glands.

CONFLICTS OF INTEREST: There is no conflict.

\section{CORRESPONDENCE TO:}

NEIL C. D'CRUZE, The World Society for the Protection of Animals, 89 Albert Embankment, London WE1 7TP, United Kingdom. Phone: 0207587 5056. Fax: 020 7793 0208. Email: cruzecontrol@gmail.com. 


\section{INTRODUCTION}

The colubrid snakes of Madagascar are highly diverse with a high level of endemism $(5,15)$. Currently, 78 species are known (5), and all of them except for Leioheterodon madagascariensis (which is also found on other Indian Ocean islands) are endemic to Madagascar (1). Approximately half of them are opisthoglyphous snakes $(5,15)$, but their potential dangerousness to humans has been poorly demonstrated $(13,14)$. Langaha is a medium-sized, slender, arboreal, mostly diurnal Malagasy colubrid genus comprised of three species (5), all of which can be quickly identified by the presence of a large leaf like rostral appendage $(5,12)$. They are opisthoglyphous and have enlarged, grooved posterior maxillary teeth (5). Despite some recent literature detailing reproduction and feeding behavior $(11,12)$ many aspects of the biology of L. madagascariensis remain poorly understood. In feeding trials Krysko (11) observed no difference in t-subdue (the time from grasping until all obvious physical movement of prey ceases) when snakes coiled around prey and when snakes did not coil around prey. This suggests that $L$. madagascariensis does not necessarily subdue prey by constriction, but rather by envenomation before swallowing (11). Although the literature suggests that this species should be approached with caution as snake bites are known to occur (7), there have been no reports that document the effects of bite by $L$. madagascariensis on humans. Here I report a case of human envenomation by $L$. madagascariensis which caused local swelling and severe temporal pain.

\section{CASE REPORT}

A male L. madagascariensis (snout-vent length: $550 \mathrm{~mm}$, tail length: 330, body mass: $43 \mathrm{~g}$ ) bit the basal segment of the fourth digit on the left hand of a man (24 years old, $70 \mathrm{~kg}$ ) on April 17, 2005, at 11:00 a.m. The bite occurred when he was attempting to record the morphological measurements of the snake as part of a biodiversity survey, which was being conducted in the semi humid dry deciduous forest of Montagne des Français (1). The snake firmly seized the finger and its enlarged maxillary teeth embedded into the dorsal side of the finger. To avoid harming the snake and to prevent further lacerations on the finger he did not attempt to force the snake to disengage immediately. Instead, he left the snake untouched and attempted to induce its voluntary release. However, the snake continued to grasp firmly, and 
repeated aggressive chewing motions some five or six times. Approximately 30 seconds after the snake had seized the finger, he suddenly felt severe sharp pain in his finger. In reaction to this sensation, approximately 1 minute after the bite, he managed to delicately disengage the snake teeth without causing further lacerations. As a result of the pain, he was not able to hold the snake with his left hand and was not able to continue taking the morphometric measurements.

The pain continued for the next 10 minutes but only slight bleeding was observed. Eleven minutes after the bite, the man began to feel local throbbing pain in addition to the persistent severe sharp pain in the finger. At this point no swelling was recognized and he cleaned the wound with antiseptic in order to prevent infection. After 30 minutes, he noticed a slight swelling on the anterior segment of the fourth digit. Severe pain began to abate an hour after the bite, but the swelling became more conspicuous. An hour and a half after the bite the swelling extended to the basal segment of the third digit of the left hand, and the basal part of the fourth digit swelled enormously. Two hours after the bite, he no longer felt sharp pain but continued to feel throbbing pain and tenderness, and he noticed that that the swelling had extended to the distal part of the hand causing it to swell enormously. In spite of the continuous local pain, he was able to have lunch as usual between 13:15 and 13:45. The swelling continued to extend, and 3 hours after the bite it covered the whole left fourth digit, distal part of the hand (both dorsal and ventral sides), and basal half of the middle and little fingers. This swelling was accompanied by intermittent severe throbbing and tenderness, especially on the fourth digit. He found it difficult to move the fingers as a result.

Five hours later, the progress of the swelling seemed to cease and he went to his tent to retire for the evening. However, he found it very difficult to sleep because of the intermittent severe throbbing and tenderness which continued throughout the night. The following morning, approximately 20 hours after the bite, only occasional slight pain on the bite site remained although swelling was still prominent. By 48 hours after the bite, slight pain occurred only when the bite mark was touched and pressed strongly. Swelling completely resolved at 12:00 p.m. on April 20. Slight pain in the finger, which was caused only by strong pressure diminished at 9:00 p.m., April 24. Signs or symptoms of general systemic effects, such as dizziness and 
N. C. D'Cruze ENVENOMATION BY THE MALAGASY COLUBRID SNAKE Langaha madagascariensis. J. Venom. Anim. Toxins incl. Trop. Dis., 2008, 14, 3, p. 549

headaches, were not recognized in this case. The patient was healthy when he was bitten, and no medical treatment was conducted.

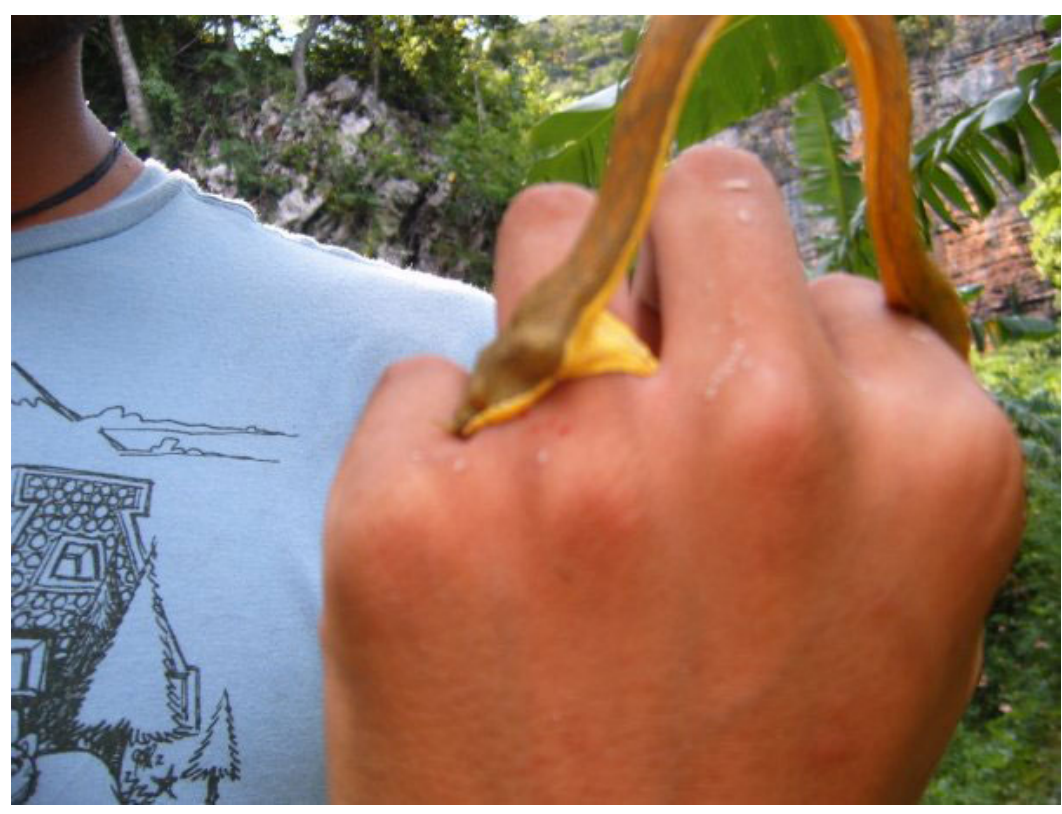

Figure 1. Langaha madagascariensis biting the subject.

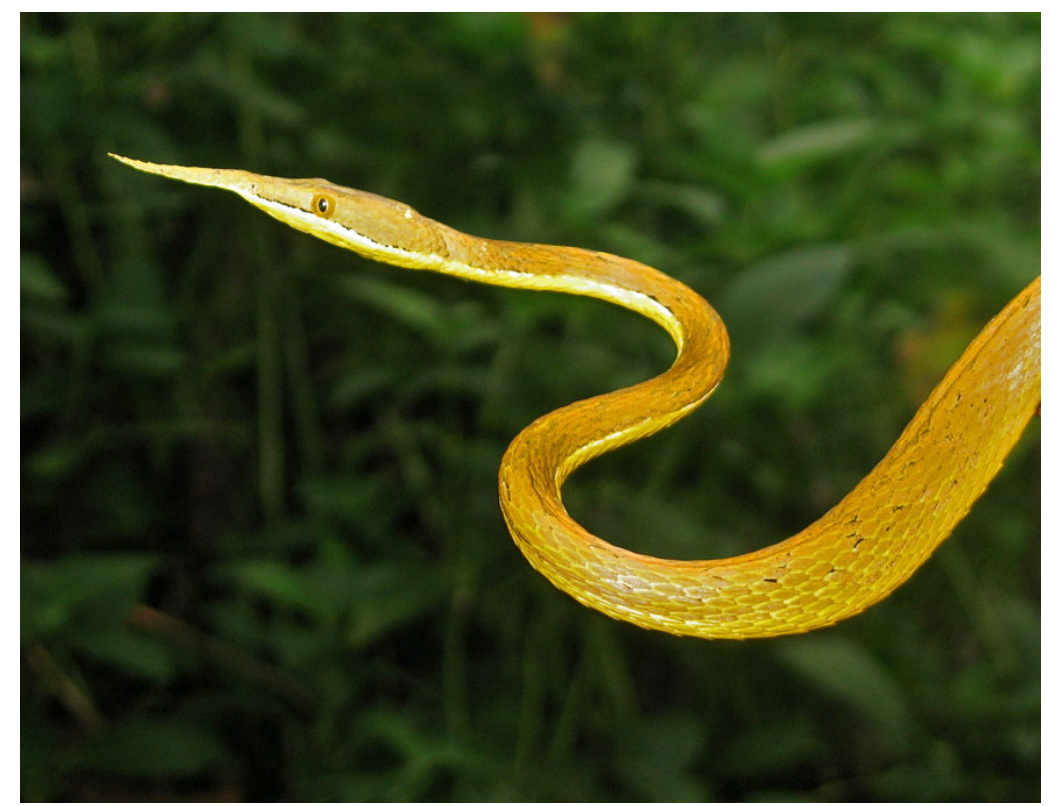

Figure 2. Langaha madagascariensis captured in the wild.

\section{DISCUSSION}

Among the 17 colubrid genera currently described in Madagascar (5), physiological effects of their bite on humans have only been reported for three opisthoglyphous (Ithycyphus, Madagascarophis and Mimophis) and one aglyphous (Leioheterodon) 
genera $(2,3,4,13,14)$. Serious local effects such as severe pain, obvious local swelling and extensive bleeding have been caused by Ithycyphous miniatus (14). The present observation provides another case which documents the serious effects of a Malagasy colubrid bite which resulted in temporal local swelling and severe pain. It is likely that the observed pharmacological effects were caused by the secretions from Duvernoy's glands $(2,14)$ although no detailed description of these glands in $L$. madagascariensis is currently available. It has been pointed out that refined definition and careful use of the term "venom" are necessary at least when used in a biological context $(8,14)$. However, it would be safe to describe the present case as human envenomation because there is evidence that small arboreal lizards seized by $L$. madagascariensis seem to be quickly immobilized (or possibly killed) (11), which fulfills the biological definition of "venom" $(8,9,10,14)$. The fact that severe pain suddenly began after 30 seconds may reflect the slow and inefficient delivery of venom associated with low pressure system and occlusion of the fang groove by the skin of the finger $(6,8,9,10,14)$.

The present report demonstrates that $L$. madagascariensis is a potentially harmful snake capable of envenoming humans. Nonetheless, despite handling this species on several occasions, I have not experienced another bite attempt such as this. It is important to note that this individual was restrained for several minutes which may have provoked the strike. It seems that the snake is basically calm and attempts to bite only as a final resort.

\section{REFERENCES}

1 D'CRUZE NC., SABEL J., GREEN K., DAWSON J., GARDENER C., ROBINSON J., STARKIE G., VENCES M., GLAW F. The first comprehensive survey of amphibians and reptiles at Montagne des Français, Madagascar. Herpetol. Conserv. Biol., 2007, 2, 87-99.

2 DOMERGUE CA. Un serpent venimeux de Madagascar: Madagascarophis colubrina. Bull. Acad. Malgache, 1962, 40, 97-8.

3 DOMERGUE CA. Un serpent venimeux de Madagascar. Observation de deux cas de morsure par Madagascarophis (Colubridé opisthoglyphe). Arch. Inst. Pasteur Madagascar, 1989, 56, 299-311. 
4 DOMERGUE CA., RICHAUD J. Activité hémolytique des secrétions des glandes de Duvernoy chez Lioheterodon (Colubridé aglyphe). Arch. Inst. Pasteur Madagascar, $1971,40,145-8$.

5 GLAW F., VENCES M. A Field guide to the amphibians and reptiles of Madagascar. 3.ed. Cologne: Vences and Glaw publishers, 2007. 496p.

6 HAYES WK., LAVIN-MURCIO P., KARDONG KV. Delivery of Duvernoy's secretion into prey by the brown tree snake, Boiga irregularis (Serpentes: Colubridae). Toxicon, 1993, 31, 881-7.

7 HENKEL FW., SCHMIDT W. Amphibians and reptiles of Madagascar and the Mascarine, Seychelles, and Comoro Islands. Florida: Krieger Publ. Co., 2000. 316 p. 8 KARDONG KV. Colubrid snakes and Duvernoy's "venom" glands. J. Toxicol. Toxin Rev., 2002, 21, 1-19.

9 KARDONG KV., LAVIN-MURCIO PA. Venom delivery of snakes as high-pressure and low-pressure systems. Copeia, 1993, 1993, 644-50.

10 KARDONG KV., YOUNG, BA. Fangs of snakes: how do open grooves inject venom into enclosed spaces? Am. Zool., 1991, 31, 51A

11 KRYSKO KL. Feeding behavior of the Madagascar leaf-nosed snake, Langaha madagascariensis (Serpentes: Colubridae: Pseudoxyrhophiinae), with an alternative hypothesis for its bizarre head structure. Afr. J. Herpetol., 2005, 54, 195-200.

12 KRYSKO KL. Reproduction in the Madagascar leaf-nosed snake, Langaha madagascariensis (Serpentes: Colubridae: Pseudoxyrhophiinae). Afr. J. Herpetol., 2003, 52, 61-8.

13 MORI A. A case of envenomation by the Madagascan colubrid snake, Leioheterodon modestus. Snake, 2002, 29, 7-8.

14 MORI A., MIZUTA T. Envenomation by the Madagascan colubrid snake, Ithycyphus miniatus. J. Venom. Anim. Toxins incl. Trop. Dis., 2006, 12, 512-20.

15 RAXWORTHY CJ. Introduction to the reptiles. In: GOODMAN SM., BENSTEAD JP. (Eds.). The Natural History of Madagascar. Chicago: The University of Chicago Press, 2003. 934-49 p. 